The field of the sulphur nitrides and related compounds (H. G. Heal), always a fascinating one, has, however, suffered from a great deal of confusion and misconception until in more recent years X-ray crystallography provided some solid evidence for a discussion of their structures. Even now, there is still great scope for further experimental and theoretical studies.

Two chapters are devoted to "Sulphuric Acid" (R. J. Gillespie) and "Fluorosulphuric Acid" (R. C. Thompson) as solvent systems, topies to which Gillespie and his group have made major contributions, and it is fitting to find him as author of the first of these.

The volume is completed by a further nine chapters. There is a subject index, but no author index. This book is of a high standard of publication and it can be recommended to all chemists interested in sulphur and its compounds, although its high cost will deter many of them from purchasing a personal copy.

R. A. SHAW

\section{HYBRID COMPUTERS}

\section{Hybrid Computation}

By George A. Bekey. Pp. xiii +464 . (Wiley: New York and London, April 1969.) $125 s$.

SINCE the appearance of the digital computer the demise of the analogue computer has been forecast. This has not as yet occurred, however, and the connexion of the two computer forms to produce numerous true hybrid computing installations has gone on unabated. Now the doom of the hybrid computer is predicted-once the numerical analysists have produced an accurate and fast digital substitute for the analogue integrator! Bekey and Karplus do not offer an opinion on when this event will occur but do give useful and valuable advice to those considering buying or setting up their own hybrid computing service.

A survey of hybrid techniques given in chapter one and chapter six indicates considerations to be taken into account when specifying a hybrid computer, including the philosophy of operation. The component parts of a hybrid computing system are also described in part one of the book, including their methods of operation, and the errors of such a system are identified, analysed and discussed (chapter five). The theoretical chapters survey numerical methods for the solution of differential equations and discuss transform techniques. For completion a chapter on software requirements is included, which is adequate but not developed as fully as other sections. The provision of suitable software determines the effectiveness of a hybrid computing system regardless of the quality of the hardware and it would have been useful to know of the author's views on this important aspect. Another omission from part one is an analysis of the effects of various word lengths and conversion speeds available with data conversion equipment (analogue to digital converters and digital to analogue converters).

Although the first part of the text is entitled theory and mechanization, the second and slightly larger part entitled applications also includes a considerable amount of theory to augment the practical applications. Theoretical discussions of methods of problem solution include chapters on parameter optimization, optimal control and random processes. The remaining chapters discuss applications drawn mainly from the aero-space field, which is not surprising as this is the field where hybrid computation began and continues to have its biggest applications.

Hybrid Computation is a very readable book which all practising hybrid programmers ought to possess as a standard reference text, because it should provide a starting point for most of their problems. The book also provides an excellent base for postgraduate courses in computational methods for control studies and might even be used for undergraduate and postgraduate studies in computing science courses.

G. C. Barney

\section{Correspondence}

\section{Students are not Employees}

SrR,--With reference to your editorial "Students are not Employees" (Nature, 222, 1213; 1969), we would like to point out the following facts which you have conveniently overlooked in your haste to mount a vehement and misinformed attack on the student body as a whole.

First, the proposals embodied in our pamphlets relate exclusively to postgraduate research workers. Also, to clear up any confusion still remaining, the work of postgraduates is as far removed from that of undergraduates as is the research done in industry. In fact, the bulk of experimental research in universities is done by postgraduates.

Sccond, the suggestion of a 35 hour week is merely a legal requirement in any contract of employment, and it must be stresscd that this was meant as a minimum requirement--most postgraduates would work far in excess of this, as they do already.

Third, we fail to understand your argument that the introduction of loans would increase starting salaries. Why should a man with a large debt be of greater value to an employer, unless it is through the law of supply and demand, when the number of postgraduates has been drastically rcduced by the loan system?

At the moment, postgraduates receive $£ 10$ per week for work that commands $£ 1,300$ per annum in industry, and have no means whereby they can keep abreast of increases in the cost of living. Introduction of a salary structure, then, would only give postgraduates the bentfits enjoyed by the rest of the community, and the status their work deserves.

\section{Yours faithfully, \\ J. P. Poyser \\ P. R. ELPHICK}

Postgraduate Action Committee,

Imperial College of

Science and Technology,

Chemistry Dopartment,

South Kensington,

London SW7.

\section{SI Units}

SLR,--I have again looked at Dr Stopes-Roe's letter (Nature, 222, 500; 1969). All four of the systems he mentions seem to imply distinctions between $B$ and $H$ and between $\mathrm{D}$ and $\mathrm{E}$ in a vacuum. He now tells me that I can have $\mathrm{B}=\mathrm{H}$ in a vacuum, but that I must accept at least one of his two possible "force-constants". Does this, or does it not, allow me to say that $\mathrm{D}=\mathrm{E}$ in a vacuum? Because I regard the statements $\mathrm{D} \neq \mathrm{E}$ and $\mathrm{B} \neq \mathrm{H}$ as equally objectionable. In two places in $\mathrm{Dr}$ Stopes-Roe's table one of these ratios appears as itself the ratio of two "constants". Am I standing on my head or my heels? I ask again, where is the clarification (misprinted as classification in my previous letter (Nature, $222,806 ; 1969)$ ) produced by introducing all these "constants"?

Neither of us wishes to prevent theoreticians from using "rational", "atomic" or any other units in their 
computations. All that $I$ ask is that they should be more careful what they publish in textbooks. It is not only students who are misled by this mania for putting dimensional constants equal to unity. Eddington once published the absurd statement that the Sun's mass can be measured in kilometres.

$$
\text { Yours faithfully, }
$$

$$
\text { H. N. V. TEMPERLEY }
$$

Department of Applied Mathematics,

University College of Swansea,

Singleton Park, Swansea.

\section{Matthew's Chance : Probability and Prejudice}

SrR,--Concerning the statistical paradox quoted in the book review "Probability and Prejudice" (Nature, 221, $291 ; 1969$ ) and commented on by Pierre E. Nel (Nature, 222,201 ; 1969), may I submit an analysis of the problom which firmly pinpoints the flaw in Matihew's reasoning and the fallacy of his optimisxu?

It may be expedient briefly to restate the problem. Of three prisoners, Matthew, Mark and Luke, two are to be executed, but Mark is not allowed to know which. $\mathrm{H}_{\Theta}$ asks the jailer "since either Mark or Luke are certainly to be executed, you will give me no information about my chances if you name one man, either Mark or Luke, who is going to be executed". Accepting this argumont, the jailer truthfully replicd "Mark is to die". Matthew now feels happier, because whereas carlier he took (quite rightly) his chance of survival of $1 / 3$, he now knows that the choice of the survivor is only between him and Luke and has consequently increased to $1 / 2$. Is Matthew right to feel happinr?

If two of the three prisoners are to be executed they may be dispatched in three possible combinations: $(a)$ Matthew + Mark, (b) Matthew + Luke, (c) Mark + Luke. Without further information each of these has clcarly equal probability. Since Matthew's chance of survival is with $(c)$, is it $1 / 3$ ?

We are told that the draw has taken place and its result is known to the jailer. Note that this statement is important because, if the situation were otherwise, the story would have a different end.

Wo (and Matthew) know that the jailer named Mark as a certain victim and with this knowledge option $(b)$ is removed as a possibility, but we still cannot distinguish between the two remaining options which therefore must be taken to be equally probable, each having now a probability of $1 / 2$. The reader will note that so far we agree with Matthew's reasoning. However, what we must; now consider and what Matthew unfortunately (not of course for his own peace of mind) forgot are the chances in this situation of the jailer actually naming Mark rather than Luke. By the rulcs of the game he was not permitted to name Matthow if he was one of the two chosen victims. We must assume that the jailer had no preference otherwise, and if the actual draw would have been (c), there was an equal chance of him either naming Luke or Mark. If the draw would have been $(a)$, on the other hand, the jailer had no choice but to namo Mark. It is in this inequality of the options open to the jailer that we find the clue to the problem.

Because the probability of the jailer naming Mark in case $(a)$ is 100 per cent and in case $(c)$ only 50 per cent, the fact that Mark's name was chosen-apart from removing option $(b)$-also implies that it is twice as likely to have come from option $(a)$ than from option $(c)$. Wo had noted earlier that each of these two options has a probability of $1 / 2$; it follows that the probability of option (c) being suggested by the jailer's disclosure is $2 / 3 \times 1 / 2=1 / 3$. This is, of course, the same probability that Matthew had to allocate to this option (his only survival chance) before the apparent indiscretion by the jailer. We arrive, of course, at exactly the same answer if we assume that the jailer names Luke.

\section{Yours faithfully,}

\section{W. J. G. Pinsker}

63 Heronscroft,

Bedford.

\section{University News}

Mr D. R. Bland, Universily of Manchester, has been appointed professor and head of the department of mathematics at the College of Aeronautics (proposed Cranficld Institute of Technology).

Dr F. C. Kafatos has been appointed professor of biology at Harvard University.

Dr G. C. Lamberg-Karlovsky has been appointed professor of anthropology at Harvard University, and curator of Near Eastern archaeology in the Peabody Museum.

Mr D. G. Anderson, Harvard University, and Mr R. W. Brockett, Massachusetts Institute of 'Technology, have been appointed Gordon McKay professors of applied mathematics at Harvard University.

Dr J. G. Buchanan, University of Neweastle upon Tyne, has been appointed to the ehair of organic chemistry at Heriot-Watt University.

Dr H. Allred has been appointed to the chair of conservative dentistry tenable at the London Hospital Medical College, University of London.

Mr D. J. Neill has been appointed to the chair of dental prosthetics tenable at Guy's Hospital Medical School, University of London.

The titic of professor of surgical science has been conferred on Dr D. G. Melrose in respect of the post held by him at the Royal Postgraduate Medical School, University of London.

The title of professor of experimental and preventive dentistry has been conferred on Dr D. C. A. Picton in respect of the post held by him at University College Hospital Medical School, University of London.

The title of professor of pharmacognosy has been conforred on Dr E. J. Shellard in respect of the post held by him at Chelsea College of Science and Technology, University of London.

The title of professor of haematology has been conferred on Dr J. W. Stewart in respect of the post held by him at the Middlesex Hospital Medical Schoo1, University of London.

The title of professor of optical design has been conforred on Dr C. G. Wynne in respect of the post held by him at Imperial College of Science and Technology, University of London.

Dr F. C. Neidhardt, Purdue University, has been appointed professor and chairman of the department of microbiology in the Medical School at the University of Michigan, in succession to Dr W. J. Nungester.

Professor S. D. Drell has been appointed deputy director of the Stanford Linear Accelerator Center (SLAC), Stanford University.

\section{Appointments}

Dr N. S. Grace, Dunlop Research Centre, Ontario, has been elected president of the Chemical Institute of Canada for 1969-70. Dr J. W. Tomecko, Industrial Rescarch Institute, University of Waterloo, Ontario, has been elected chairman of the institute's board of directors. 